\title{
Corrigendum: Sizing of Hybrid Energy Storage Systems for Inertial and Primary Frequency Control
}

\author{
Erick Fernando Alves ${ }^{1 *}$, Daniel dos Santos Mota ${ }^{1}$ and Elisabetta Tedeschi ${ }^{1,2}$ \\ ${ }^{1}$ Department of Electric Power Engineering, Norwegian University of Science and Technology, Trondheim, Norway, ${ }^{2}$ Department \\ of Industrial Engineering, University of Trento, Trento, Italy
}

Keywords: low-inertia systems, energy storage, inertial control, primary control, frequency stability, power system design

\section{A Corrigendum on}

Sizing of Hybrid Energy Storage Systems for Inertial and Primary Frequency Control by Alves, E. F., Mota, D. d. S., and Tedeschi, E. (2021). Front. Energy Res. 9:649200. doi: 10.3389/fenrg. 2021.649200

OPEN ACCESS

Edited by:

Hong Fan,

Shanghai University of Electric Power,

China

*Correspondence: Erick Fernando Alves erick.f.alves@ntnu.no

Specialty section:

This article was submitted to Smart Grids,

a section of the journal Frontiers in Energy Research

Received: 31 May 2021 Accepted: 21 June 2021

Published: 12 July 2021

Citation:

Alves EF, Mota DdS and Tedeschi E (2021) Corrigendum: Sizing of Hybrid

Energy Storage Systems for Inertial and Primary Frequency Control. Front. Energy Res. 9:718210. doi: 10.3389/fenrg.2021.718210
In the original article, there was a mistake in Figures $\mathbf{9}$ and $\mathbf{1 0}$, and Tables $\mathbf{1}$ and $\mathbf{2}$ as published.

There was a mistake in the parameters of the validation model presented in Section $\mathbf{3}$ Results [available in the reference Alves, E. F. (2021)]. The normalized moment of inertia reported in the article $(M=5.1 \mathrm{~s})$ was wrongly multiplied by 4 in the MATLAB/Simulink model. Due to this error, Figures 9 and 10 reported incorrect dynamics, and Tables 1 and 2 reported incorrect values. The values for parameters $\left(t_{a}-t_{0}\right)$ and $\left(t_{b}-t_{a}\right)$ in Table 1 were incorrectly reported as $25 \mathrm{~s}$ and $15 \mathrm{~s}$, respectively. The correct values are $11 \mathrm{~s}$ and $18 \mathrm{~s}$, respectively. The value for parameter $E_{e s 1}$ in Table 2 was incorrectly reported as $101.76 \mathrm{kWh}$, the correct value is $60 \mathrm{kWh}$. In addition to Figures 9 and 10 , and Tables $\mathbf{1}$ and 2, corrections have subsequently been made to various reported values throughout the article, namely in Section 3 Results, Sub-sections 3.1 study: a wind-powered offshore platform in the North Sea, 3.2 Sizing of the Energy Storage System, and 3.3 Sizing Validation. The corrected Figures 9 and 10, and Tables 1 and 2 appear below.

The authors apologize for this error and state that this does not change the scientific conclusions of the article in any way. The original article has been updated.

\section{REFERENCES}

Alves, E. F. (2021). Efantnu/hybrid-ess-design: Review 1 Release. version v1.1Zenodo. doi:10.5281/zenodo.4601067

Copyright $(2021$ Alves, Mota and Tedeschi. This is an open-access article distributed under the terms of the Creative Commons Attribution License (CC BY). The use, distribution or reproduction in other forums is permitted, provided the original author(s) and the copyright owner(s) are credited and that the original publication in this journal is cited, in accordance with accepted academic practice. No use, distribution or reproduction is permitted which does not comply with these terms. 


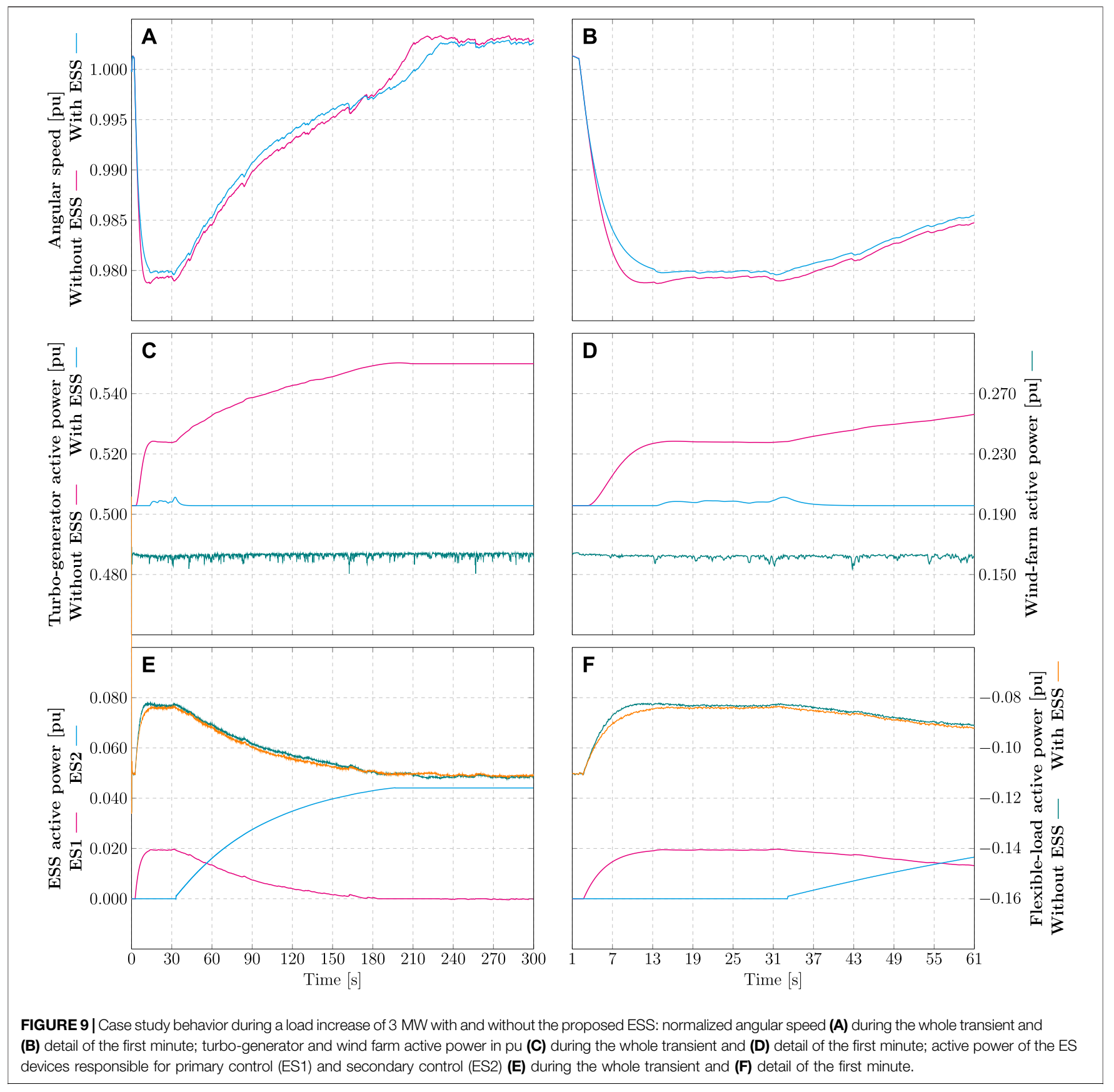




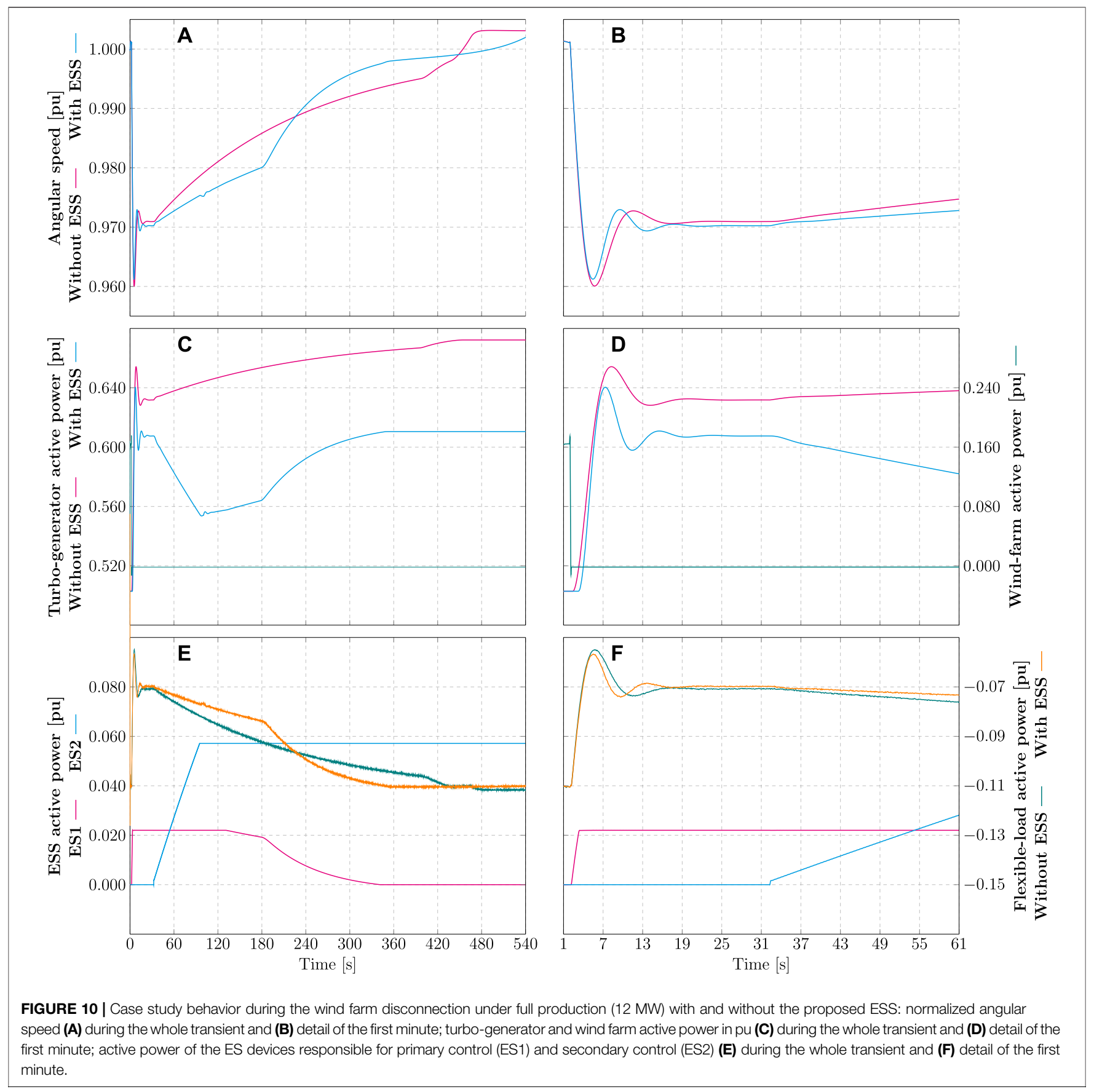


TABLE 1 | Parameters of the ACPS of an offshore oil and gas platform in the Norwegian continental shelf and the requirements for its converter-interfaced ESS.

Param

$S_{b}$

$r_{t r}$

$M_{G T}$

$D_{\text {flex }}$

$P_{E L Y}$

$\left(t_{a}-t_{0}\right)$

$\left(t_{c}-t_{b}\right)$
Value

$70 \mathrm{MW}$

$0.05 \mathrm{pu}$

$5.1 \mathrm{~s}$

1.09 pu

$6 \mathrm{MW}$

$11 \mathrm{~s}$

$120 \mathrm{~s}$
Param

$\omega_{S}$

$r_{s s}$

$D_{\text {min }}$

$D_{\text {es }}$

$P_{F C}$

$\left(t_{b}-t_{a}\right)$
Value

$377 \mathrm{rad} \mathrm{s}^{-1}$

$0.02 \mathrm{pu}$

$2.25 \mathrm{pu}$

$1.16 \mathrm{pu}$

$4 \mathrm{MW}$

$18 \mathrm{~s}$

TABLE 2 | Summary of the ESS parameters obtained using the proposed procedure.

\begin{tabular}{|c|c|c|c|}
\hline Param & Value & Param & Value \\
\hline$P_{\text {es } 1}$ & $1.54 \mathrm{MW}$ & $E_{e s 1}$ & $60 \mathrm{~kW} \mathrm{~h}$ \\
\hline$U_{d c}$ & $1500 \mathrm{~V}$ & $\Delta \bigcup_{d c}^{\max }$ & $150 \mathrm{~V}$ \\
\hline$T_{r}$ & $2.1 \mathrm{~ms}$ & $\Delta P_{d c}^{\max }$ & $360.5 \mathrm{~kW}$ \\
\hline$P_{\text {losses }}^{\text {es } 1}$ & $25 \mathrm{~kW}$ & $C_{d c}$ & $1.7 \mathrm{mF}$ \\
\hline$P_{g c}$ & $7.72 \mathrm{MW}$ & $S_{g c}$ & 9.65 MVA \\
\hline$U_{2 n}$ & 675 V & $\Delta I_{g c a}$ & $0.25 \mathrm{pu}$ \\
\hline$f_{S W}$ & $5.4 \mathrm{kHz}$ & $L_{g c}$ & $5.61 \mu \mathrm{H}$ \\
\hline$L_{g}$ & $6.92 \mu \mathrm{H}$ & $C_{c}$ & $2.5 \mathrm{mF}$ \\
\hline$f_{\text {res }}$ & $1.80 \mathrm{kHz}$ & $R_{C}$ & $0.189 \mathrm{~m} \Omega$ \\
\hline
\end{tabular}

